\title{
Behavioural consequences of density-dependent habitat use in juvenile cod Gadus morhua and G. ogac: the role of movement and aggregation
}

\author{
B. J. Laurel ${ }^{1, *}$, R. S. Gregory ${ }^{1,2}$, J. A. Brown ${ }^{1}$, J. K. Hancock ${ }^{1}$, D. C. Schneider ${ }^{1}$ \\ ${ }^{1}$ Memorial University of Newfoundland, Ocean Sciences Centre, St. John's, Newfoundland A1C 5S7, Canada \\ ${ }^{2}$ Department of Fisheries and Oceans, St. John's, Newfoundland A1C 5X1, Canada
}

\begin{abstract}
Fish behaviour can change to accommodate a variable environment, but changes in behaviour have not been considered in the context of density-dependent habitat use. In Bonavista Bay, Newfoundland, we measured how fish density movement and schooling behaviour changed with habitat in 2 gadids, Atlantic cod Gadus morhua and Greenland cod Gadus ogac, using a combination of field-seines, mark-recapture and laboratory experiments. Density estimates from seines $(n=427)$ over $5 \mathrm{yr}$ (1996, 1998 to 2001) indicated that these species associated with eelgrass but periodically were detected in high abundance over unvegetated habitat (i.e. sand). Within-site catch variation indicated both species aggregated more in sand than eelgrass habitat, and, in Atlantic cod, aggregations over sand increased as density in eelgrass increased. Although such patterns in catch data could be interpreted as due to the effects of differential mortality between habitats, a mark-recapture experiment indicated that both species of cod were not site-attached and moved between seine locations. Furthermore, video-analysis from laboratory experiments demonstrated that cod formed tighter aggregations over sand compared to eelgrass habitats. Our results suggest that juvenile cod modify their behaviour with changing density, possibly as a means of exploiting poor-quality habitats when high-quality habitats are saturated with conspecifics. Consequently, habitat suitability for Atlantic cod may be a dynamic rather than fixed variable in density-dependent habitat models.
\end{abstract}

KEY WORDS: Density-dependence $\cdot$ Habitat selection · Atlantic cod · Greenland cod · Aggregation · Shoaling

\section{INTRODUCTION}

Predation in aquatic systems can have profound effects on the distribution of many species of fish (Sih 1987). Predators can shape prey fish distribution either directly through selective mortality (e.g. Tupper \& Boutlier 1995a, Steele 1999) or indirectly through riskinduced behaviour such as schooling or use of protective habitat (see Godin 1997 for review). It is likely both direct and indirect effects of predation on fish distribution are magnified during the early life stages of fish when predation risk is highest (e.g. Houde 1987, Sogard 1997).

Complex habitats (e.g. rock, woody debris, coral, submerged vegetation) are often used by fish as a means of reducing predation risk (Savino \& Stein 1982, Gotceitas \& Colgan 1989, Gotceitas \& Brown 1993). In particular, highly structured aquatic vegetation (e.g. eelgrass) has received much attention as a refuge habitat (Orth et al. 1984, Gotceitas et al. 1997, Linehan et al. 2001, Laurel et al. 2003a), likely due to its wide distribution and high productivity relative to neighbouring unvegetated sites (Orth et al. 1984, Bell \& Pollard 1989). The likelihood of encountering and capturing prey is reduced in eelgrass (Gotceitas et al. 1997), and, consequently, predation rates are typically lower despite sometimes higher predator densities in these habitats (Linehan et al. 2001, Laurel et al. 2003b). It is therefore not surprising that structured habitat is often used as nursery habitat by many species of recently 
settled marine fish (Bell \& Pollard 1989, Levin 1991, Sogard \& Able 1991, Edgar \& Shaw 1995, Grant \& Brown 1998a, Matilla et al. 1999, Heck et al. 2003).

Despite the benefits of using complex habitats, fish may be forced to use high-risk habitats (e.g. sand, bedrock) when preferential habitats are saturated by conspecifics. The decline in habitat selection with increasing population abundance was first outlined by Fretwell \& Lucas (1970) and has subsequently formed the basis for frequency-dependent modeling, i.e. idealfree distribution. When populations are low, individuals should be restricted to habitats offering the highest fitness benefits, e.g. high survival and growth. As population density increases, individual fitness benefits decrease (via competitive interactions), and, consequently, poorer quality habitats become more attractive. These relationships have been explored and reviewed for many taxa, including fish (MacCall 1990, Kramer et al. 1997).

One shortcoming with density-dependent habitat models is that they assume the organism's behaviour is the same across all habitats. Such an assumption is problematic because changes in behaviour can modify the fitness benefits associated with a particular habitat. Density-dependent habitat models rely on a static measure of habitat suitability, equal to the fitness benefits acquired by an organism at zero density. The fitness benefits of a habitat cannot be static if the organism has a dynamic behavioural strategy. Therefore, density-dependent changes in behaviour should also be considered when modeling habitat suitability and predicting distribution.

Fish adopt different strategies to compensate for the increased predation risk associated with specific habitats. Immediate, short-term responses include freezing (motionless) (e.g. Brown 1984, Radabaugh 1989), reduced activity (Rahel \& Stein 1988) and increased flight-initiation distances (Ydenberg \& Dill 1986). However, employing these tactics can result in reduced mating success (e.g. Hastings 1991) and lost foraging opportunities (e.g. Williams \& Brown 1991). Alternatively, group tactics (e.g. schooling, shoaling) may be more viable long-term solutions when using poorer-quality habitat. Shoaling has been shown to reduce predation risk through increased predator confusion (e.g. Milinski 1979, 1985), dilution (Foster \& Treherne 1981, Krebs \& Davies 1991) and vigilance (Bertram 1978). The cost of group association (e.g. food competition, increased conspicuousness) may be ameliorated by increased food searching (Pitcher et al. 1982), group defense (Krebs \& Davies 1991) and increased hydrodynamic efficiency (Weihs 1975). However, the use of shoaling as an alternative tactic in habitats with low suitability has not been considered in the context of density-dependent habitat selection.
Little is known of mechanisms of variable habitat use of juvenile Atlantic cod. Since the collapse of Atlantic cod populations off Newfoundland, Age 0 juvenile cod have been largely restricted to inshore areas (Dalley \& Anderson 1997), where they are commonly associated with complex bottom habitats (Gotceitas et al. 1997, Grant \& Brown 1998a). Field experiments have demonstrated that these fish prefer to settle in eelgrass in July/August (Laurel et al. 2003a) and remain there until late November, when they presumably move to deeper waters (Methven \& Bajdik 1994). Eelgrass has been shown to reduce predation risk for Age 0 juvenile cod in both laboratory (Gotceitas et al. 1997) and field (Linehan et al. 2001, Laurel et al. 2003b) experiments. Despite their preference for eelgrass, however, juvenile cod are occasionally observed over less-structured habitats such as sand and cobble (Lough et al. 1989, Tupper \& Boutlier 1995a,b, Laurel et al. 2003a). Juvenile cod are believed to move little immediately following settlement (Tupper \& Boutilier 1995a,b, Grant \& Brown 1998a), and, consequently, the occupation of less-structured habitats is taken to be the result of indiscriminate settlement patterns. By implication, temporal variation in distribution following settlement is the result of selective predation across habitats (Tupper \& Boutilier 1995a,b). However, Schneider et al. (1999) demonstrated that movement prevails over mortality at the scales studied by Tupper \& Boutilier $(1995 a, b)$, i.e. ca. $<1000 \mathrm{~m}$ and $<100 \mathrm{~d}$. Furthermore, a recent study by Laurel et al. (2003a) suggested that temporal variation in distribution is the result of postsettlement movement and habitat mediated aggregation. Therefore, the mechanisms of variable habitat use in these fish remains unclear.

In this study, we gathered data from the field and laboratory to determine how juvenile cod density, movement and schooling behaviour interact to affect habitat use patterns. Specifically, we asked (1) whether juvenile cod aggregate differently between habitats in years of low and high abundance, and (2) whether such aggregations are the result of behaviour (i.e. movement and schooling patterns). For the first question, we used seine data collected over 5 yr (1996, 1998 to 2001) to determine if catch aggregation of juvenile cod is related to habitat type and the density of conspecifics. To address the second question, we used a mark-recapture experiment to determine if juvenile cod moved at scales greater than a seine haul. This experiment was followed by a laboratory study in which we observed whether juveniles school differently between sand and eelgrass habitats. The implications of a changing behavioural strategy between years of high and low abundance are discussed in the context of density-dependent habitat selection. 


\section{MATERIALS AND METHODS}

Study location. Fieldwork was carried out along shallow coastal areas ( $\leq 6 \mathrm{~m}$ depth) in Newman Sound, Terra Nova National Park (TNNP), located within Bonavista Bay, Newfoundland (Fig. 1). Newman Sound is a fjord, $41 \mathrm{~km}$ long and 1.5 to $3.0 \mathrm{~km}$ wide, that is divided into 2 basins by a sill that rises to a depth of $18 \mathrm{~m}$. The inner sound has a maximum depth of $55 \mathrm{~m}$, whereas the outer sound ranges to a depth of $300 \mathrm{~m}$ at its seaward end. Coastal substrate ranges from mud to bedrock, often with associated vegetative cover (Zostera marina eelgrass, in mud, sand and gravel substrates; the macroalgae Laminaria digitata Lamouroux, Agarum cribrosum Bory, Chondrus crispus Stackhouse, Fucus oesiculosus L. and Ascophyllum nodosum [L.] Le Jolis, on coarse substrates). However, of these vegetated habitats, eelgrass is the most common and contiguously found in Newman Sound. Seasonal temperatures in the sound range from $20^{\circ} \mathrm{C}$ in late August to $-1.0^{\circ} \mathrm{C}$ in early December.

Seine surveys. Abundance of Age 0 juvenile cod was determined using demersal beach seines in 1996 and 1998 to 2001. Seines were deployed $55 \mathrm{~m}$ from shore from a $6 \mathrm{~m}$ boat and pulled toward shore by 2 individuals standing $16 \mathrm{~m}$ apart. The seine sampled $880 \mathrm{~m}^{2}$ of demersal habitat up to $2 \mathrm{~m}$ from the bottom. Seine collections were made only during daylight hours $\pm 2 \mathrm{~h}$ of low tide. Fish collected in the seine were transferred to large containers filled with seawater at ambient temperature. Juvenile cod were counted and identified before being returned alive to their site of capture. SCUBA observations have shown that the seine samples $95 \%$ of the fish community within its path (Gotceitas et al. 1997). A full description of the seine, mesh size and deployment method is found in Schneider et al. (1997).

In each year, seines were pulled every 2 wk over 4 unvegetated 'sand' sites (Mt. Stamford, MS; Newbridge, NB; Canning's Cove, CC; Little South Broad Cove, LSB) and 8 'eelgrass' sites (Big Brook, BB; Dockside, DS; White Rock, WR; Mistaken Cove, MS; Buckley's Cove, BC; Heffern's Cove, HC; Minchin's Cove, $\mathrm{MC}_{i}$ South Broad Cove, SB) between mid-July and late November (Fig. 1). However, in 1996 sites were characterised by 2 unvegetated sites $(\mathrm{NB}, \mathrm{CC})$ and 4 vegetated sites (BB, DS, WR, BC) during the first 3 sampling periods. An additional unvegetated site (MS) and 2 vegetated sites (HC, MC) were added to the survey for the remainder of sampling in that year. Full sampling of sites occurred in the years 1998, 1999, 2000 and 2001. 'Eelgrass' sites consisted of mixed mud/silt bottoms, with small amounts of sand and gravel overlayed with silt and supporting moderate to dense eelgrass. 'Sand' sites were comprised of sand or gravel and contained little to no vegetation in the path or near the vicinity of the seine.

Nearshore studies in Newfoundland have shown that Gadus morhua settle in at least 2 distinctive recruitment pulses. The first pulse occurs in August/ September, which is then followed by a 2 second pulse occurring approximately 30 d later (Methven \& Bajdik 1994, Grant \& Brown 1998a). In contrast, G. ogac settle in a single recruitment pulse in July/August (Laurel et al. 2003a).

Mark-recapture experiment. A mark-recapture experiment was performed between 16 August and 3 September 1999 on the western shore of inner Newman Sound in Terra Nova National Park $\left(48^{\circ} 35^{\prime} \mathrm{N}\right.$, $53^{\circ} 55^{\prime} \mathrm{W}$ ) to determine if juvenile cod are highly mobile or strongly site-attached. The site was chosen because it contained a contiguous band of eelgrass and it was conducive to pulling multiple adjacent seines, i.e. few boulders and other obstructions. Fifteen adjacent seine sites (16 m wide) were initially marked with flagging tape along $274 \mathrm{~m}$ of unobstructed shoreline; the survey area encompassed $13504 \mathrm{~m}^{2}$. Five of the interior sites of the survey area proved to be difficult to seine, so these were not surveyed during the markrecapture experiment. The remaining 10 sites representing the survey area are illustrated in Fig. 2.

We collected 1109 Gadus spp. (47\% G. morhua; $53 \%$ G. ogac) on 18 August from Site 4 (i.e. location 0 $\mathrm{m})$ and mass-marked with fluorescent grit following the procedure described by Phinney et al. (1973). The marking apparatus consisted of a marking gun (commercial sandblast gun) retrofitted with a $5 \mathrm{~mm}$ orifice and attached canister holding Saturn yellow fluores-

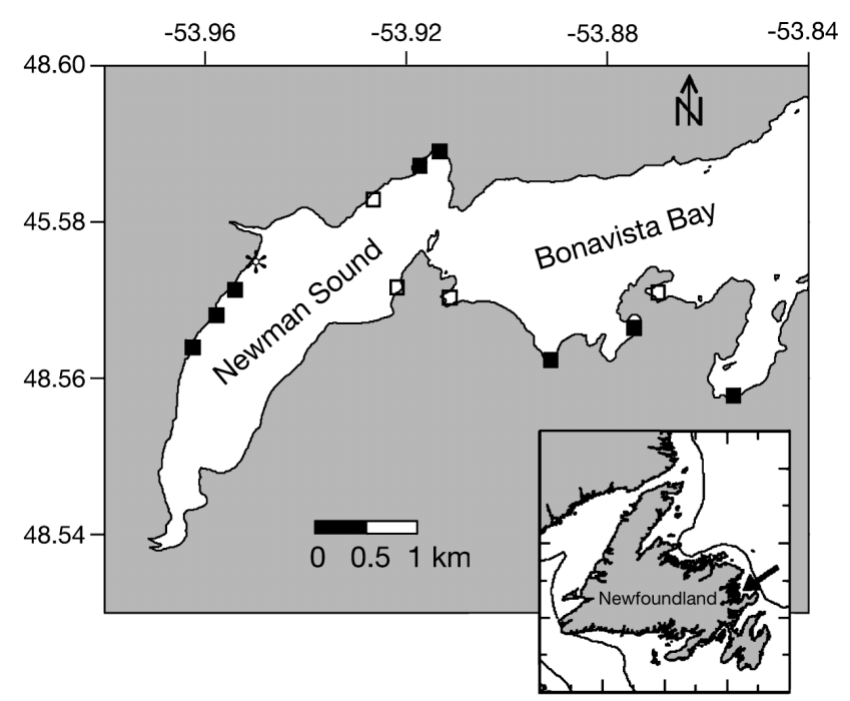

Fig. 1. Study area in Newman Sound, Bonavista Bay, Newfoundland, showing sand (ㅁ) and eelgrass ( $\square$ ) seine locations. Mark-recapture effort $(* *)$ was conducted on the western shore of the sound 


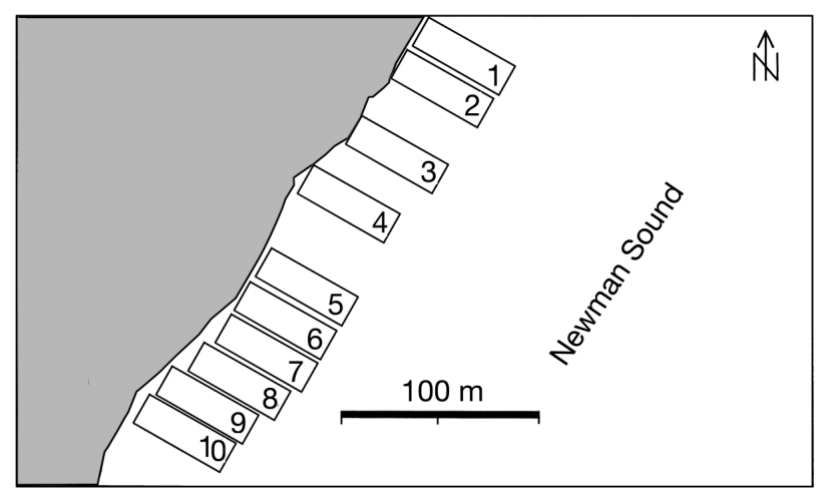

Fig. 2. Illustration of the layout of sites seined to measure movement of Gadus morhua and G. ogac on a 219 m section of shoreline in Newman Sound, Bonavista Bay, Newfoundland, between 18 August and 3 September 1999. Marine habitat within and beyond the seine sites consists of eelgrass Zostera marina

cent grit (DayGLO Color). The marking apparatus was attached to a SCUBA cylinder with a high-pressure hose and regulator that reduced air pressure to $550 \mathrm{kPa}$ during marking. Fish (50 to 250 at a time) were marked in a plastic tub ( $0.5 \mathrm{~m}$ width, $0.5 \mathrm{~m}$ height, $1.0 \mathrm{~m}$ length) with a screen bottom (1 $\mathrm{mm}$ mesh). The plastic tub was nested in a similar-sized tub holding ambient seawater to minimise the time fish spent out of water. The marking gun was held ca. $40 \mathrm{~cm}$ from the fish and sprayed for 2 to $3 \mathrm{~s}$. Fish were then transferred to partially submerged, plastic holding pens at the site of capture. Marked individuals were released back into the site of capture (Site 4; Fig. 2) $10 \mathrm{~h}$ following the last batch marking. Mark retention is nearly $100 \%$ within the first 2 mo of marking juvenile fish (Phinney et al. 1973), and preliminary trials on juvenile cod placed in holding pens demonstrated no mark loss over a 3 wk period.

A recapture seining series was initiated on Day 1 (15 h after release) and repeated on Days 2, 6, 9 and 16. One seine haul was pulled at each site (1 to 10) on each recapture day using 2 seining teams. Team A and Team B sampled simultaneously; Team A started at Site 5 and worked towards Site 1, while Team B started at Site 10 and worked towards Site 6 . Captured juvenile cod were transferred to holding containers with seawater and examined in a dark tent under ultraviolet light for presence of fluorescent marks. All fish were transferred to holding containers and released after seining was completed for the day, after which fish were released back into the site of their recapture.

Laboratory experiments. Fish collection: Juvenile Age 0 Gadus morhua ( 70 to $90 \mathrm{~mm}$ standard length) were caught by beach seine in early October from additional eelgrass sites elsewhere in Newman Sound and transferred to the laboratory. Fish were held in
$1 \times 1 \times 0.5 \mathrm{~m}$ flow-through tanks at ambient water temperature and fed a mixture of chopped herring and commercial pelleted food. Fish were allowed to acclimate to laboratory conditions for a period of $2 \mathrm{wk}$ prior to initiating experiments.

Experimental design: Juvenile cod distribution was digitally videotaped over sand and simulated eelgrass in a large flow-through tank $(2.0 \times 1.5 \times 0.4 \mathrm{~m})$ maintained at 5 to $10^{\circ} \mathrm{C}$. A digital video camera, fixed with a wide-angle lens, was mounted $2.2 \mathrm{~m}$ directly above the tank. The field of view and focus of the camera were locked to maintain a clear, perpendicular view of the entire tank and its inhabitants. The camera could be operated remotely from an adjacent room outfitted with a video-screen to start and stop trials. Illumination was provided by 2 light stands ( $1.8 \mathrm{~m}$ high) on opposite sides of the tank; each light stand was fitted with 2 halogen lamps (300 W). Lamps were angled into each side of the tank to highlight fish as well as intentionally create a shadow on the tank bottom.

Bottom habitat was switched repeatedly between trials to either unvegetated sand or simulated eelgrass. Sand $(<1 \mathrm{~mm})$ was washed and placed into the tank to cover the entire bottom at a thickness of $10 \mathrm{~cm}$. Eelgrass was manufactured by attaching green, plastic ribbon $(0.8 \mathrm{~cm}$ width, $20 \mathrm{~cm}$ height) to mats of galvanised wire fencing at a density of 400 blades $\mathrm{m}^{2}$. Field experiments have shown that these blade densities are preferred by juvenile cod during settlement (Laurel et al. 2003a). During placement of eelgrass into the tank, fencing was fully covered by a sand layer so that only the ribbon was visible during trials. Simulated eelgrass emerging from the substrate varied in length between 17 and $19 \mathrm{~cm}$. Field experiments have shown that similarly constructed eelgrass attracts (Laurel et al. 2003a) and reduces (Laurel et al. 2003b) predation of juvenile cod.

Five experimentally naïve Age 0 juvenile cod (Gadus morhua; $7.8 \pm 0.14 \mathrm{~cm}$ ) were transferred from holding tanks to the experimental tank using a 21 transparent glass container with ambient seawater. Fish were allowed to acclimate to the temperature of the experimental tank by placing the holding container in the centre of the tank for $15 \mathrm{~min}$. Fish were then released into the tank and filmed for a $1 \mathrm{~h}$ period. All operations to manipulate the camera were conducted in a separate room to minimise disturbances during a trial. Following each trial, fish were collected by dip net and moved to a separate holding tank. A total of 10 trials $(1 \mathrm{~h}$ each) in each habitat (eelgrass and sand) were recorded over $3 \mathrm{wk}$.

Video analysis: Digital video recordings were uploaded to a computer with image analysis software (Matrox Inspector) to gather 3-dimensional positioning and orientation data for each juvenile cod. Frame grabs of video were insufficient by themselves because 
fish were difficult to distinguish against the heterogeneity of the habitat. Instead, short $10 \mathrm{~s}$ clips of video were captured and looped repeatedly from a reference frame. Fish were digitally marked at the reference frame, while the video looped to reveal the position of each fish. Reference frames along with $10 \mathrm{~s}$ video clips were captured at $3 \mathrm{~min}$ intervals for $57 \mathrm{~min}$ during each trial ( $\mathrm{n}=20$ reference frames/trial).

From each reference frame we gathered the orientation and position in space $(x, y, z$ coordinates) of each fish. Orientation was acquired by drawing a digital line from head to tail of each fish from each reference frame ( $\mathrm{n}=5$ angles/frame, $\mathrm{n}=100$ angles/trial). The software outputs an angle $\left(0^{\circ}\right.$ to $\left.360^{\circ}\right)$ based on the counterclockwise difference between digitally marked fish and a 3 o'clock reference line.

The calculation of fish position in 3 dimensions followed the procedure outlined by Laurel (2003). Digital images were calibrated at the far field such that any measurements assumed fish were at the substrate level. Fish positions were measured by placing a digital point at the anterior end of each cod in each reference frame $(\mathrm{n}=5 x, y$ coordinates/frame, $100 x, y$ coordinates/trial). From each digital point, the Cartesian coordinate system of the software output a fish position in a 2-dimensional plane $(x, y)$. Measurements were also taken of the distance of each fish's shadow cast on the substrate from 1 of the 2 light sources. The last known shadow distance was used in rare instances when the walls of the tank obstructed both shadows cast by a fish. Using the measurements from image analysis (i.e. shadow distance and $x, y$ coordinates) as well as the known light and camera positions $(x, y, z)$, we calculated true fish position in 3 dimensions from vector equations described by Laurel (2003).

Data analysis. Field seines: Juvenile cod densities estimated from seine catches were examined using quantile-quantile plots of percent abundance versus percent area to determine the degree of aggregation of fish in the field, i.e. Lorenz curves (Dagum 1985). Plots were constructed for eelgrass and sand separately for each year by first calculating the percentage of the total population within a year associated with a single seine haul $i$ from either eelgrass or sand sites:

$$
n_{i}=100\left(w_{i}+1\right) / \bar{E}
$$

where $W_{i}$ is the number of fish caught in a seine haul $i$ and $\bar{E}$ indicates the mean catch per haul. These data were compared against the percentage area associated with each tow $\left(A_{i}=100 C_{i}\right)$, where $C_{i}$ was the proportion of the annual catch in a single seine haul $i$. Seine hauls were sorted by $n_{i}$ and plotted as cumulative percent area against cumulative percent abundance for each year, species and habitat. A highly concave curve indicates high aggregation (i.e. shoaling or high mortality), whereas increased linearity with a slope approaching 1 indicates an even distribution (i.e. territoriality or low mortality) of fish among seine hauls. The range in concavity is related to the statistical distribution (e.g. normal, Poisson, negative binomial) of the catch data (Fig. 3). The total area underneath each curve was integrated $(k)$ to determine the discrepancy from a perfectly even distribution i.e. 1:1 line. Then, $k$ was plotted against the corresponding yearly mean catch to determine if density was related to aggregation as measured by $k$. Data were then logtransformed and regressed to determine if $k$ increased with annual abundance. Such a relationship would indicate a density-dependent effect on aggregation.

We also examined within-site aggregation over the course of a season (July to November). Within-site catch variability for each year and each species was determined using coefficients of variation (CV) of biweekly catch data $\left(w_{i}+1\right)$. These data were regressed against the log-transformed total catch within each site for each species within a year $\left[\log \left(W_{\text {tot }}+N_{\text {tot }}\right)\right]$. Residuals from regression met the assumptions of normality and homogeneity.

Mark-recapture: Movement rate was calculated by regressing the number of recaptures against time:

$$
\ln (N+1)=\alpha+\beta(T)
$$

where $N$ was the number of recaptures of juvenile cod and $T$ was the time in days. A constant $(N+1)$ was added to the equation to include possible days when

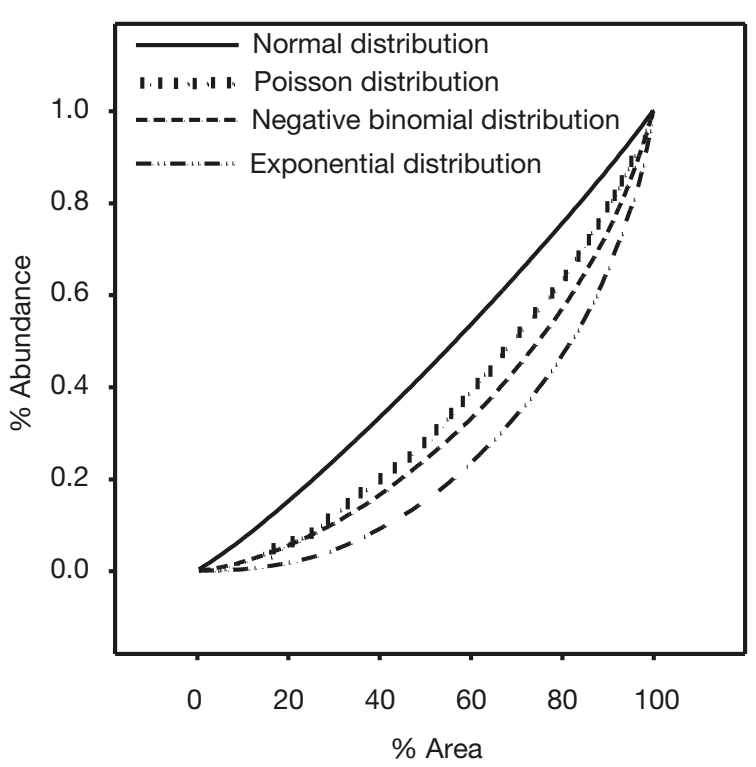

Fig. 3. Quantile-quantile plots for randomly generated data from normal, Poisson and negative binomial distributions $(k<1)$. High concavity suggests high aggregation of an organism in time or space 
0 fish would be recaptured. We determined movement rate from the slope $(100 \times \beta)$ and expressed it as the percent of fish per day leaving the survey area.

We also examined whether movement patterns resembled a simple diffusive process. A simple diffusion model predicts fish move indiscriminately in or among habitats. Alternatively, fish not corresponding with a simple diffusion model would indicate some degree of habitat or site selection. To test the simple diffusion model, we examined the standard deviations of the mean distribution along the beach on each day. The standard deviation on each day was logarithmically transformed and regressed against time in days:

$$
\ln (S)=\alpha+\beta \ln (T)
$$

where $S$ is the standard deviation of the mean location of captures in a day (metres away from release point) and $T$ is the time (d). We then used the mathematical definition of diffusion:

$$
2 D=\frac{\Delta v}{\Delta t}
$$

where $v$ is variance and $t$ is time, to derive the regression model that describes simple diffusion:

$$
\ln (S)=0.5 \ln (2 D)+0.5 \ln (T)
$$

We used the resulting slope $(\beta=0.5)$ as a benchmark for comparing model and field recapture data. A linear relationship where $\beta=0.5$ indicates fish movement occurs by simple diffusion. Alternatively, a linear relationship where $\beta \neq 0.5$ suggests a process other than simple diffusion.

Video data: We determined the degree of aggregation in tank trials by calculating distances between all fish in each reference frame. The distances between one fish in space $(A x, A y, A z)$ and a second fish $(B x, B y$, $B z$ ) was calculated using the following equation:

$$
\text { Dist }=\sqrt{\left(d x^{2}+d y^{2}+d z^{2}\right)}
$$

where $d x=A x-B x, d y=A y-B y$ and $d z=A z-B z$. The total sum of all possible distances between fish in each reference frame ( $\mathrm{n}=10$ distances/frame) was then used to calculate an aggregation coefficient ( $\mathrm{n}=1 /$ frame, $\mathrm{n}=20 /$ trial). We used 1-way ANOVA with repeated measures to determine if mean aggregation coefficients within each trial $(\mathrm{n}=10$ eelgrass, $\mathrm{n}=10$ sand) differed between habitats. Habitat (eelgrass or sand) formed the between-group factor in the model. Time (min) of observation (e.g. $0,3,6,9, \ldots, 57)$ within the trial was examined as a within-group factor.

We determined how groups of fish oriented over different habitats $(n=10$ angle differences/frame, $n=200$ angle differences/trial) by examining the similarity between angles within a reference frame. The minimal sum of the angle difference $\left(A_{\mathrm{D}}\right)$ between each fish and its neighbours for each reference frame was calculated using the following equation:

$$
A_{\mathrm{D}}=\min \left|\sum_{i=1}^{n} \mathrm{Ang}_{i}-\mathrm{Ang}_{i+1}\right|
$$

Angle differences were transformed so that $\mathrm{Ang}_{\mathrm{i}}-$ $\mathrm{Ang}_{i+1}<180$. If $\mathrm{Ang}_{i}-\mathrm{Ang}_{i+1}>180$, angles were adjusted using the equation:

$$
360-\left[\mathrm{Ang}_{i}-\mathrm{Ang}_{i+1}\right]
$$

We used the minimal sum, which consisted of 1 reference fish relative to its 4 other neighbours $(n=5$ angle differences/sum), as the test statistic from which to measure group orientation. Lower sum values indicated that fish were oriented in the same direction, whereas high sums suggested that fish were moving in separate directions. Mean minimal angle sums (n = 20/trial) were compared between habitat treatments using 1-way ANOVA with repeated measures $(\mathrm{n}=10$ eelgrass, $\mathrm{n}=10$ sand). The assumptions for computing p-values were checked by examining residuals for normality and homogeneity. Habitat (eelgrass or sand)

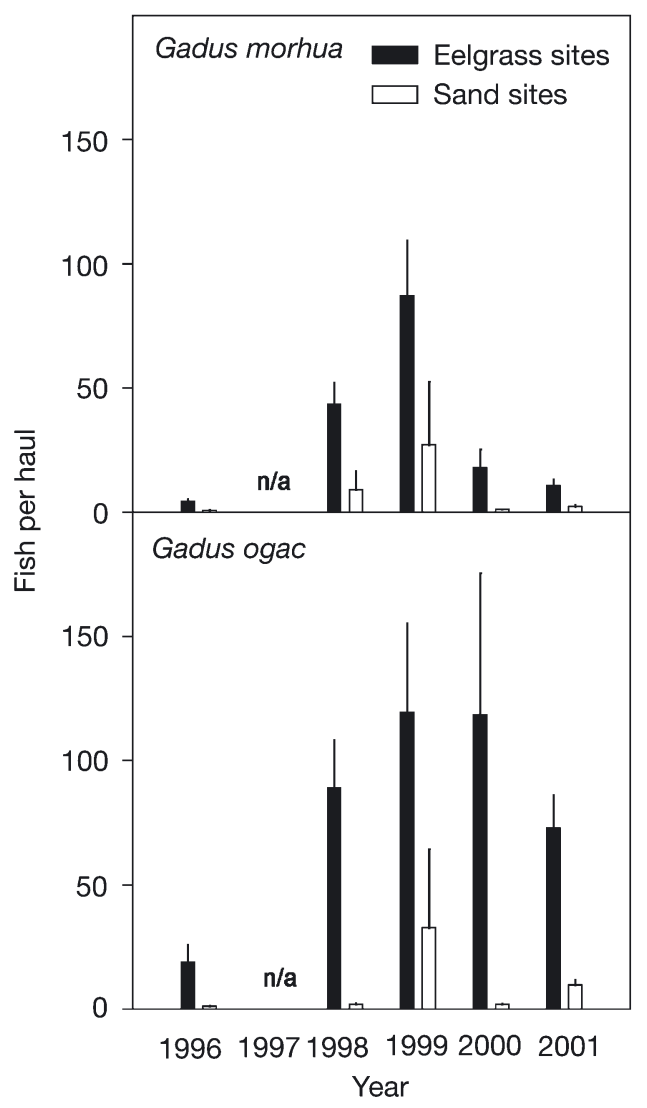

Fig. 4. Gadus morhua and G. ogac. Mean seasonal (July to November) catch at sand and eelgrass sites from 1996 and 1998 to 2001. Values between 1998 and 2001 are based on 70 to 80 seine hauls \pm 1 SE. 1996 values are based on 10 to 20 seine hauls $\pm 1 \mathrm{SE}$ 


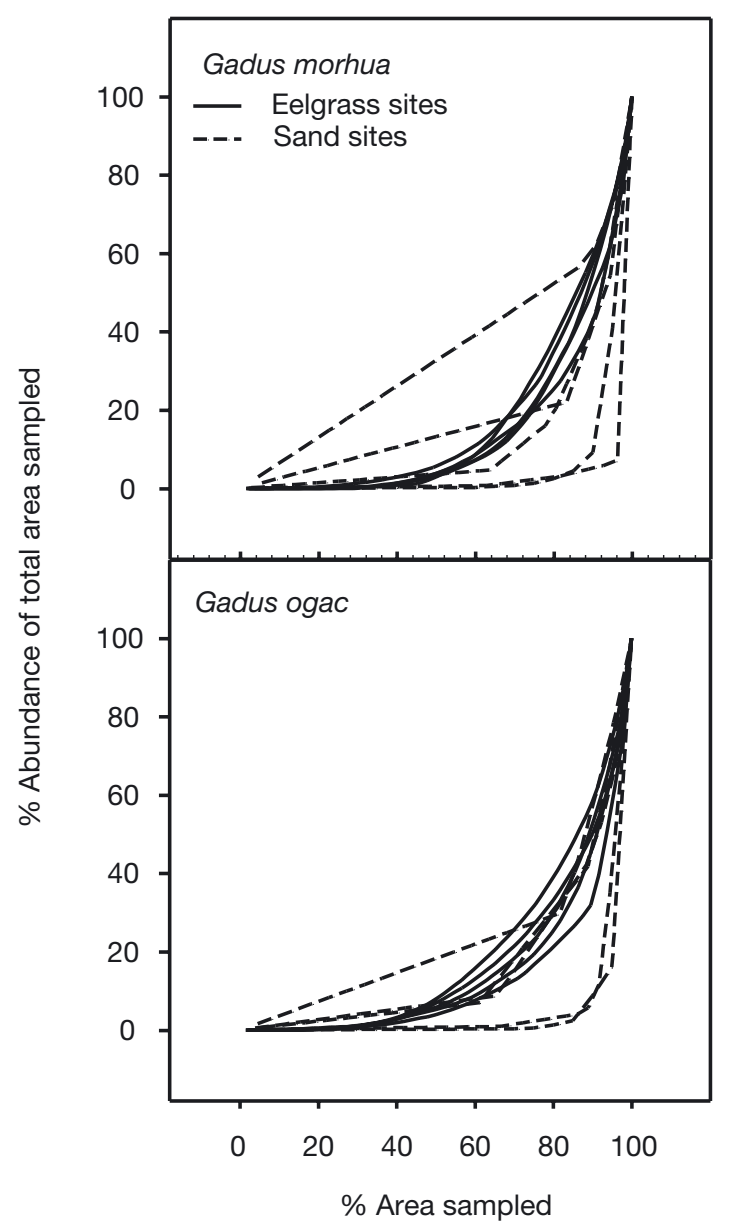

Fig. 5. Gadus morhua and G. ogac. Quantile-quantile plots of interannual seine catches $(1996,1998$ to 2001). Each curve comprises the seasonal catch (July to November) of fish in a single year. A highly concave curve indicates high aggregation (i.e. shoaling or high mortality), whereas increased linearity, with a slope approaching 1 , indicates an even distribution (i.e. territoriality or low mortality) of fish among seine hauls

formed the between-group factor in the model and time (min) of observation within the trial was examined as a within-group factor.

\section{RESULTS}

\section{Field catch data}

There was high interannual variability in late summer and autumnal catches of both Gadus morhua and G. ogaC (Fig. 4). This was most pronounced in G. morhua, with more than an order of magnitude difference in mean catch, ranging from a high catch in 1999 $\left(87.3 \pm 22.3\right.$ fish haul $^{-1}$; mean $\left.\pm \mathrm{SE}\right)$ to a low catch in 2001 (4.6 \pm 0.9 fish haul $\left.^{-1}\right)$. In contrast, G. ogac ranged from a high catch in $1999\left(118.5 \pm 56.9\right.$ fish haul $\left.^{-1}\right)$ to a low catch in $1996\left(19.1 \pm 7.0\right.$ fish haul $\left.{ }^{-1}\right)$.

Both Gadus morhua and G. ogac aggregated more when in sand habitats than eelgrass habitats in most years (Fig. 5), but the degree of aggregation was highly variable in sand habitats between years for both species. The interannual variability in the degree of G. morhua aggregations $(k)$ over sand was significantly related to interannual fluctuations in density $\left(\mathrm{n}=5, \mathrm{r}^{2}=0.93, \mathrm{p}=0.004 ;\right.$ Fig. 6$)$. However, no relationship was found for G. morhua at eelgrass sites $\left(\mathrm{n}=5, \mathrm{r}^{2}=0.11, \mathrm{p}=0.636\right)$ or for $G$. ogac in either sand $\left(n=5, r^{2}=0.28, p=0.103\right)$ or eelgrass $\left(n=5, r^{2}=0.01\right.$, $\mathrm{p}=0.979$ ). Therefore, only G. morhua became more aggregated over sand habitats when abundance in eelgrass habitats was higher.

Within-site temporal variability was correlated with abundance in sand for both Gadus morhua (n $=17$, $\left.r^{2}=0.79, p<0.001\right)$ and G. ogac $\left(n=17, r^{2}=0.83, p<\right.$ 0.001 ), but not in eelgrass (G. morhua: $\mathrm{n}=39, \mathrm{r}^{2}=$ $0.02, \mathrm{p}=0.444 ; G$. ogac: $\mathrm{n}=39, \mathrm{r}^{2}=0.01, \mathrm{p}=0.829$; Fig. 7). These data suggest that, for both cod species, high abundance within a sand site is due to a few large aggregations of fish. In contrast, individual eelgrass sites were much less variable at high abundance, indicating consistent catches over time in this habitat.

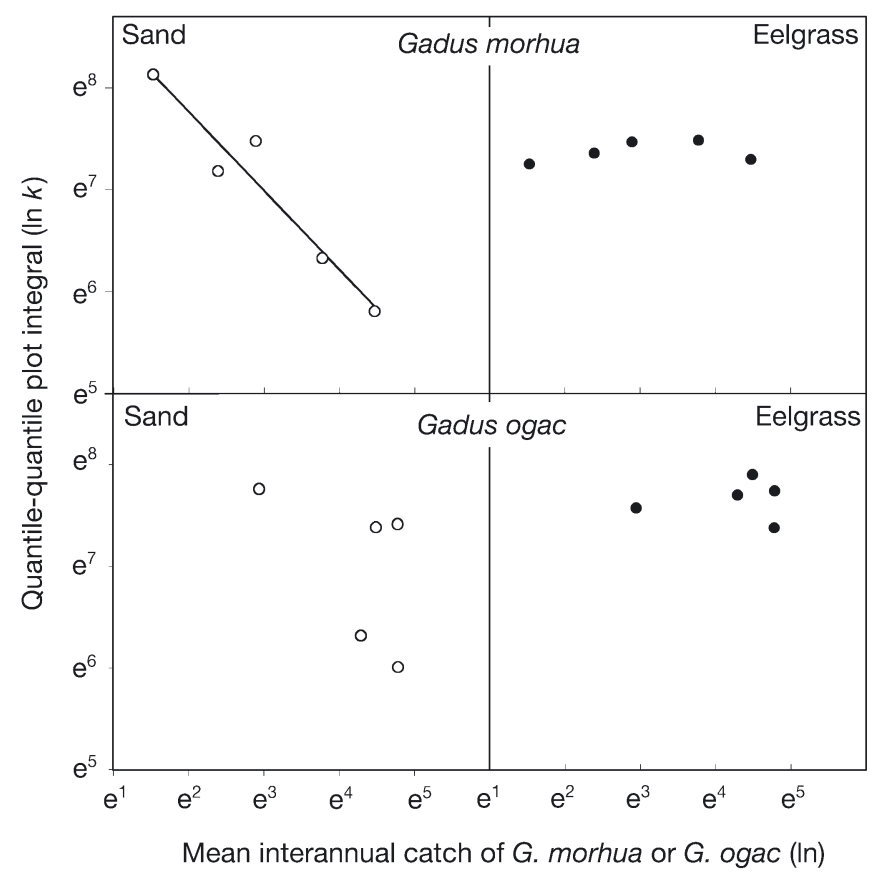

Fig. 6. Gadus morhua and G. ogac. Relationship of yearly aggregation (quantile-quantile plot integration $k$ ) and yearly abundance in either sand $(0)$ or eelgrass $(\bullet)$. High values on the $y$-axis indicate low levels of spatio-temporal aggregation 


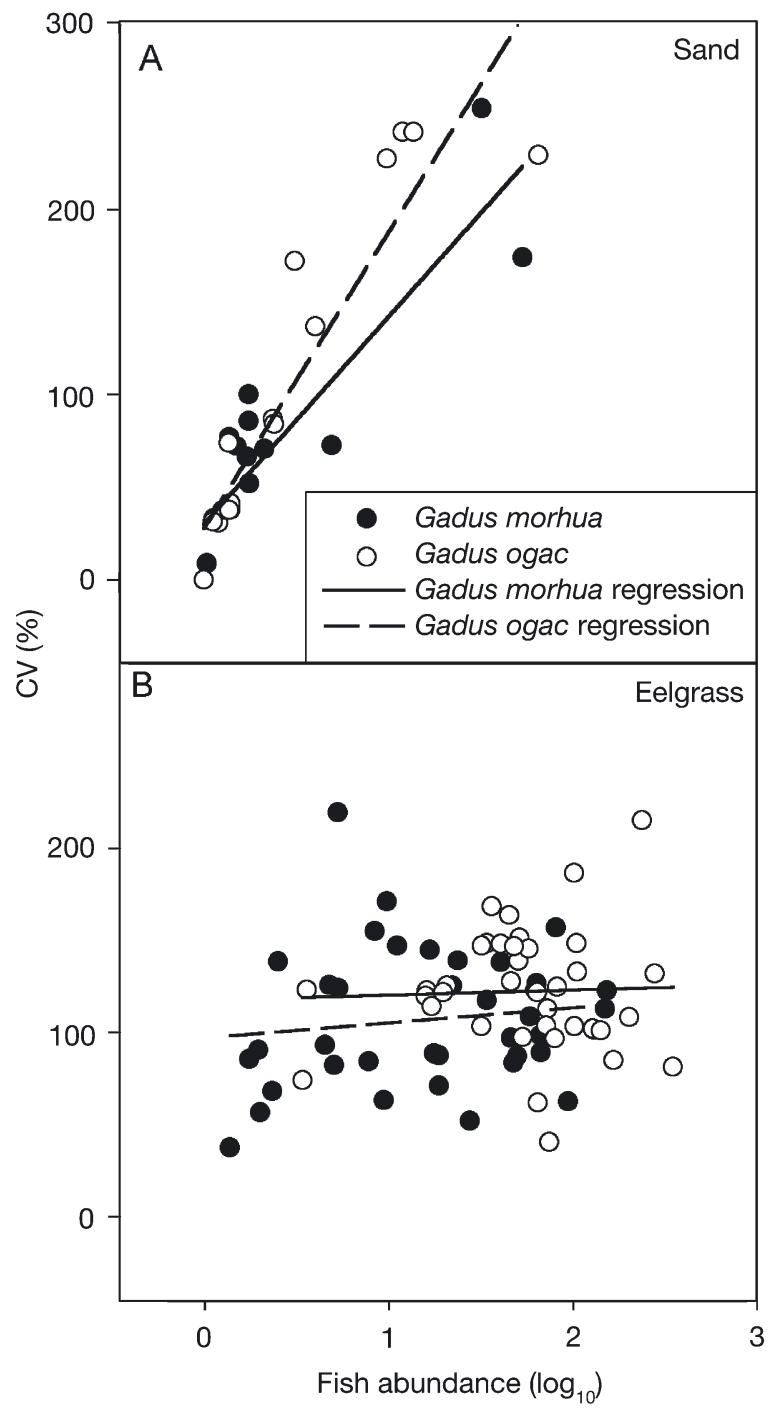

Fig. 7. Gadus morhua and G. ogac. Coefficients of variation against seasonal abundance at seine sites comprised of either (A) sand or (B) eelgrass. Plotted values represent the coefficient of variation (CV) calculated from 8 to 10 seine hauls within a year (1996, 1998 to 2001) at a single location

\section{Mark-recapture experiment}

There was a significant negative relationship $\left(\mathrm{r}^{2}=\right.$ $0.84, p=0.0181$ ) between the number of daily recaptures and time (Fig. 8). We interpret this as resulting from cod movement rather than mortality, since marked individuals were caught progressively further from the area of release on successive days (Table 1). The species composition of recaptures was $63 \%$ Gadus morhua and $37 \%$ G. ogac over the entire experiment. From the regression equation:

$$
\ln (N+1)=2.70-0.167 \times T
$$

we calculated the mixed-species movement rate of juvenile cod as $16.7 \% \mathrm{~d}^{-1}$ from an area of $13035 \mathrm{~m}^{2}$ $(237 \times 55 \mathrm{~m})$.

Significantly fewer fish were caught on Day 6 compared to other days $\left(F_{1,49}=11.81, \mathrm{p}=0.0012\right)$. Recapture effort on Day 6 occurred during heavy rainfall, and fish may have moved into deeper water to avoid contact with freshwater run-off. We therefore ran movement models (standard deviation with time) with Day 6 included and excluded. Including Day 6 into the regression produced a non-significant result $\left(F_{1,3}=\right.$ $0.1028, \mathrm{p}=0.779$ ):

$$
\ln (S)=3.306-0.112 \ln (T)
$$

In contrast, the regression with Day 6 excluded was significant $\left(F_{1,2}=173.8, \mathrm{p}=0.0482\right)$ :

$$
\ln (S)=3.317+0.111 \ln (\mathrm{T})
$$

The slope from the latter equation $(\beta=0.1)$ deviated substantially from the slope calculate for simple diffusion $(\beta=0.5)$. Therefore, the pattern of dispersal for Age 0 cod in the study area was not simple diffusion.

\section{Video trials}

Video analysis indicated that juvenile cod were more aggregated over sand habitat than eelgrass habitat (ANOVA with repeated measures; $F_{1,18}=$ 21.716, p $<0.001$, Fig. 9). Within-subject analysis indicated a measurable effect of aggregation over time in sand $\left(F_{19,179}=4.165, \mathrm{p}=0.028\right)$ or eelgrass $\left(F_{19,179}=8.025, \mathrm{p}=0.011\right)$. Fish were highly aggregated in both habitats early in the trial as a result of being released from a common starting position in

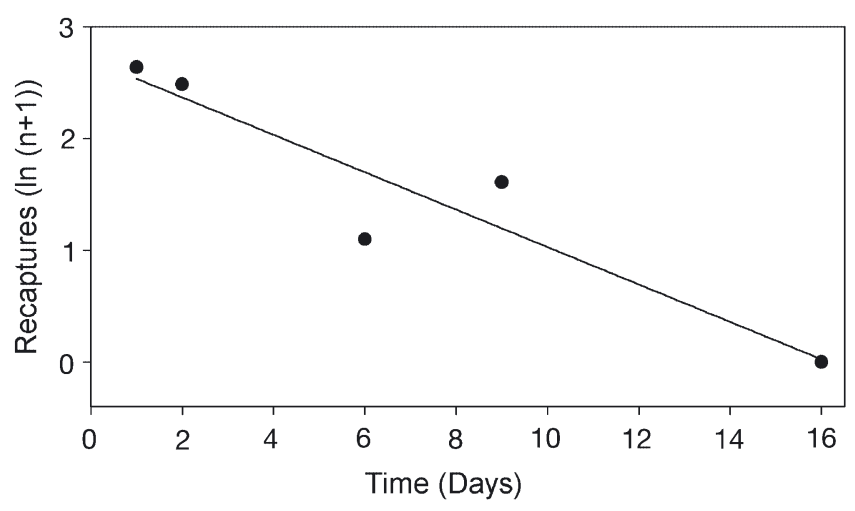

Fig. 8. Gadus morhua and G. ogac. Recaptures of juvenile cod (fish haul-1) along a $219 \mathrm{~m}$ section of shoreline in Newman Sound. Total recaptures consisted of $63 \%$ G. morhua and $37 \%$ G. ogac 


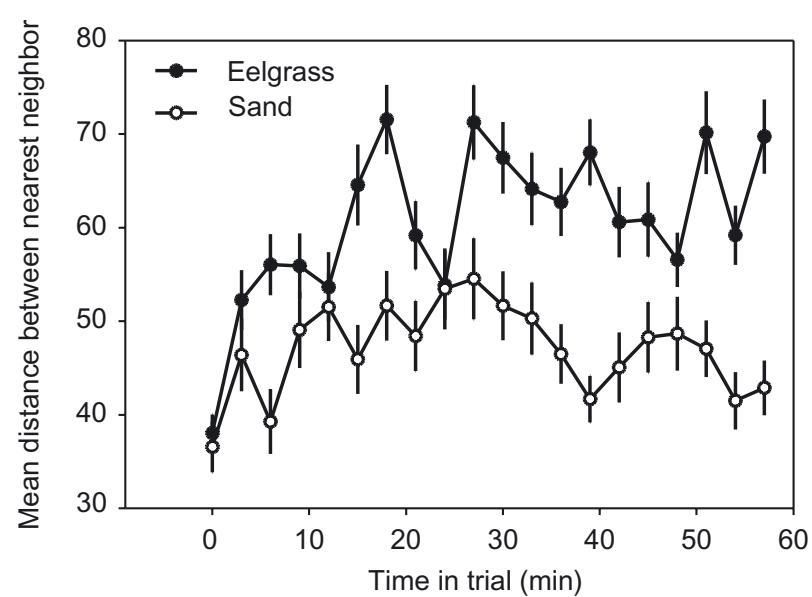

Fig. 9. Gadus morhua. Degree of shoaling (inter-individual distance) over time ( $\mathrm{min}$ ) in experimental tanks with eelgrass ( $\mathrm{n}=10$ trials) or sand ( $\mathrm{n}=10$ trials). Plotted values represent the cumulative distance of each fish to its neighbour from 10 trials $\pm 1 \mathrm{SE}$

the tank. Increases in juvenile cod dispersal in both eelgrass and sand appeared to level after 20 min into the trial, but fish in eelgrass treatments were clearly more dispersed at this point (Fig. 9). No aggressive behaviour was noted between individuals in either treatment.

There was weak evidence that propensity to swim in parallel differs between habitats. Fish over sand habitat were oriented in a common direction more so than fish in eelgrass habitat. However, the analysis showed this to be just outside the statistical alpha (ANOVA with repeated measures; $F_{1,18}=3.36, \mathrm{p}=$ 0.087; Fig. 10). Within-subject analysis also indicated no measurable change in orientation over time in sand $\left(F_{19,179}=0.165, \mathrm{p}=0.828\right)$ or eelgrass $\left(F_{19,179}=\right.$ $0.122, \mathrm{p}=0.751)$.

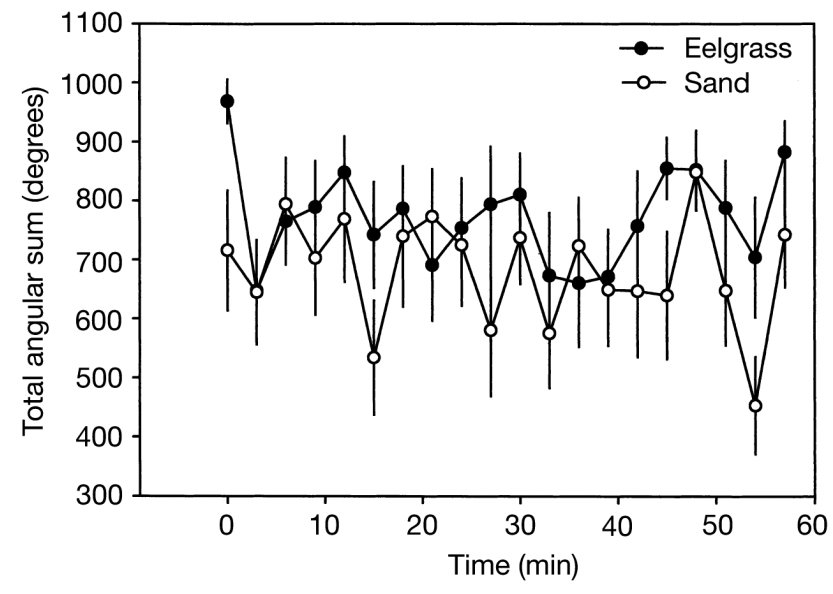

Fig. 10. Gadus morhua. Degree of orientation (angle separation between individuals) in experimental tanks outfitted with eelgrass ( $\mathrm{n}=10$ trials) or sand $(\mathrm{n}=10$ trials). Low values along the $y$-axis indicate fish are orienting in the same direction. Plotted values calculated from angle sums of 5 individuals from 10 trials $\pm 1 \mathrm{SE}$

\section{DISCUSSION}

The relationship of juvenile cod and habitat has been explored from field observations (e.g. Tupper \& Boutilier 1995a,b, Gotceitas et al. 1997), laboratory experiments (Fraser et al. 1995, Gotceitas et al. 1995, Lindholm et al. 1999) and field experiments Linehan et al. 2001, Laurel et al. 2003a,b). However, this study provides the first evidence that observed variation in catch of Age 0 juvenile cod is the result of habitatinduced changes in aggregative behaviour, e.g. shoaling or schooling. Juvenile cod use of low-complexity habitats (i.e. sand) was ephemeral and aggregative in nature. More significantly, however, these aggregation patterns for Gadus morhua were magnified over sites with low habitat complexity in high-abundance years.

Table 1. Gadus morhua and G. ogac. Number of Age 0 juvenile cod recaptured by beach seine over 10 seine sites along a $219 \mathrm{~m}$ section of shoreline in Newman Sound. Juvenile cod $(n=1109)$ were captured, marked and released on Day 0 at Site $4(0 \mathrm{~m})$ and recaptured on Days 1, 2, 6 and 9. *: no recaptures; also, none were recaptured at Site 1 (95 m) or on Day 16

\begin{tabular}{|c|c|c|c|c|c|c|c|c|c|c|}
\hline \multirow{2}{*}{ Day } & \multirow{2}{*}{ Species } & \\
\hline & & $\begin{array}{c}10 \\
(-124 \mathrm{~m})\end{array}$ & $\begin{array}{c}9 \\
(-100 \mathrm{~m})\end{array}$ & $\begin{array}{c}8 \\
(-83 \mathrm{~m})\end{array}$ & $\begin{array}{c}7 \\
(-70 \mathrm{~m})\end{array}$ & $\begin{array}{c}6 \\
(-51 \mathrm{~m})\end{array}$ & $\begin{array}{c}5 \\
(-35 \mathrm{~m})\end{array}$ & $\begin{array}{c}4 \\
(0 \mathrm{~m})\end{array}$ & $\begin{array}{c}3 \\
(29 \mathrm{~m})\end{array}$ & $\begin{array}{c}2 \\
(78 \mathrm{~m})\end{array}$ \\
\hline \multirow[t]{2}{*}{1} & G. morhua & * & * & * & 1 & 1 & 2 & 6 & * & * \\
\hline & G. ogac & * & * & * & 1 & * & 1 & 1 & * & * \\
\hline \multirow[t]{2}{*}{2} & G. morhua & 1 & ** & * & 1 & * & * & 2 & 2 & * \\
\hline & G. ogac & * & 2 & * & * & * & * & * & 3 & * \\
\hline \multirow[t]{2}{*}{6} & G. morhua & * & * & * & * & * & * & * & * & * \\
\hline & G. ogac & * & * & 1 & 1 & * & * & * & * & * \\
\hline \multirow[t]{2}{*}{9} & G. morhua & * & * & * & 1 & * & 1 & 1 & * & * \\
\hline & G. ogac & * & * & * & $*$ & * & $*$ & * & * & 1 \\
\hline
\end{tabular}


Therefore, our study provides a clear example of a density-dependent, induced change of behaviour in a marine fish. Consequently, habitat suitability for Atlantic cod may be a dynamic rather than static function if aggregative behaviour modifies fitness in these habitats.

The effects of space limitation have been widely explored in marine fish. Organisms may use poorerquality habitat (e.g. low food, high risk) when highquality habitat (e.g. high food, low risk) becomes saturated (e.g. MacCall 1990, Kramer et al. 1997). Fish settling in poor-quality habitat may either die (e.g. Connell \& Jones 1991, Tupper \& Boutilier 1995a) or face poor growth (Sogard 1992). Our data from field sampling, mark-recapture and video observations all demonstrated that fish settling in poor habitat can also switch to another behaviour. This 'behaviour switching' hypothesis is supported in several lines of evidence. First, Gadus morhua and G. ogac were caught in sand habitats infrequently, and, when present, they generally occurred at high densities. Second, video observations confirmed that G. morhua aggregated more over sand. Finally, mark-recapture data demonstrated that both cod species move extensively following settlement. We suggest that this aggregation behaviour in open habitats either reduced predator risk or was in response to the possibly unique foraging opportunities available there (Savino \& Stein 1982, Pitcher 1986).

Living in groups has a number of antipredator and foraging advantages. Increased shoal cohesion has been shown to occur in fish when exposed to increased predation risk (Andorfer 1980, Magurran \& Pitcher 1987). Possible antipredator benefits include increased predator detection (Bertram 1978), confusion (Milinski 1979, 1985) and dilution (Foster \& Treherne 1981, Krebs \& Davies 1991, but see Pitcher 1986 for alternative view). These mechanisms may offset the cost of increased conspicuousness of group living by reducing predation rates for aggregative species (Calvert et al. 1979, Foster \& Treherne 1981), including fish (e.g. Neill \& Cullen 1974, Tremblay \& Fitzgerald 1979). Foraging benefits include increased search rates and information gathering and sharing (Pitcher et al. 1982). Studies have shown that fish in large groups can allocate more time to foraging in open substrates since less time need be spent refuging in complex habitats (Magurran \& Pitcher 1983). However, under certain conditions, habitat-specific behaviour can lead to increased mortality. For example, gobies increase their activity levels in open habitats, which ultimately leads to increased predation rates (Tallmark \& Evans 1986). It is therefore difficult to speculate on the advantage of juvenile cod shoaling in sand in years of high abundance since we did not measure the fitness conse- quences of such behaviour. Based on the mixed evidence of benefits stemming from habitat-specific behaviour, it may be that shoaling over poor-quality habitat is the result of juvenile cod 'making the best of a bad situation' rather than a fitness strategy suitable in all years.

High densities of juvenile cod were found associated with eelgrass in all years, suggesting this is a preferred nursery habitat for these 2 species. Complex habitats such as eelgrass generally support a higher number of species and density of fish than habitats of low complexity (Orth et al. 1984, Bell \& Pollard 1989). Eelgrass often supports higher densities of food, namely in the form of pelagic and epiphytic zooplankton. Macrophytes also reduce the risk of predation for young fish from larger piscivores (e.g. Werner \& Gilliam 1984, Mittelbach 1986), including juvenile cod from known predators such as older conspecifics (Bogstad et al. 1994) as well as red hake Urophycis tenuis and sculpin Myoxocephalus spp. (Linehan et al. 2001, Laurel et al. 2003b). Juvenile cod have also been shown to use the interstitial spaces of less complex mineral substrates such as cobble and gravel for predator avoidance (e.g. Lough et al. 1989, Gregory \& Anderson 1997). However, the substrate particle size at the sand sites was ca. $<1 \mathrm{~mm}$, and therefore, unsuitable for cover. Predation risk is higher over substrates with particle sizes $<4$ mm (i.e. sand; Gotceitas \& Brown 1993), and, consequently, Age 0 cod are seldom observed over small particulate substrates either inshore (Laurel et al. 2003a) or offshore (Lough et al. 1989).

There are conflicting reports on the range and degree of Age 0 juvenile cod movement following settlement. Age 0 juvenile cod have been observed defending areas of habitat in the field (Tupper \& Boutlier 1995a,b) and the laboratory (Gotceitas \& Brown 1993). Tupper \& Boutlier (1995a,b) also document high site fidelity and limited within-habitat movement for juvenile cod. However, our data stand in contrast to previous discussions of territorial behaviour and limited movement. In both of the above studies, variable use of habitat was attributed to differential, predator-induced mortality between habitats rather than movement. Grant \& Brown (1998a) observed some movement in Gadus morhua in nearshore areas of Newfoundland, but they suggested these movements were infrequent and restricted to a few hundred metres over an entire season. A subsequent study (Grant \& Brown 1998b) showed a diel inshore-offshore movement of juvenile cod, possibly in response to temporal changes in prey availability and predator risk.

Mark-recapture data from the present study suggest juvenile cod movements are spatially and temporally greater than previously reported. Furthermore, juvenile cod movement patterns did not resemble simple 
diffusion, suggesting that juvenile cod were making habitat decisions among eelgrass sites. However, movement patterns should be interpreted with caution due to the low number of overall recaptures of juvenile cod. Differences in reported movements between studies may be the result of local habitat characteristics. Our study was conducted in a contiguous eelgrass bed, whereas previous work has been conducted along obstructed shorelines (e.g. Grant \& Brown 1998a,b). Other differences in reported movement rates may be linked to unique genetic or phenotypic aspects of the cod populations studied (e.g. Ruzzante et al. 1998). Species of fish can have static and resident components even at small spatial scales (Stott 1967, Taylor 1990, Heggenes et al. 1991, Freeman 1995). Therefore, variable movement within genetically discrete populations should be expected. Moreover, growth rates of cod between populations are highly variable. Growth of juvenile cod in St. Mary's Bay can reach $2.27 \mathrm{~mm} \mathrm{~d}^{-1}$ (Tupper \& Boutilier 1994b) relative to ca. $1.5 \mathrm{~mm} \mathrm{~d}^{-1}$ by the cod collected in our study (R.S.G. \& B.J.L. unpubl. data). Phenotypic variability (e.g. growth, body size, etc.) often corresponds with a change in behaviour, including strategies of feeding (e.g. Lavin \& McPhail 1987), predator defense (e.g. Bronmark \& Miner 1992) and territoriality (e.g. Taylor 1990). These differing strategies may ultimately contribute to differing patterns of movement in and among habitats.

Movement rates in fish can also be influenced by the degree of habitat heterogeneity. Fish movement may decrease in preferred habitats if those habitats are isolated or surrounded by unfavourable habitat, i.e. 'oasis effects' (Virnstein \& Curran 1986, Schroeder 1987, Sogard 1989). Grant \& Brown (1998a) report limited movement of juvenile cod between sites following settlement in nearshore areas, suggesting there were large sections of unfavourable habitat between sampling sites. Age 0 juvenile cod are restricted to shallow, nearshore habitat such as eelgrass, possibly due to increased predation with depth (Linehan et al. 2001) and reduced habitat complexity beyond the littoral zone (Gregory \& Anderson 1997). Mark-recapture studies conducted between areas of varying habitat and depth may therefore misrepresent the capacity of movement in juvenile cod. In our study, juvenile cod movement was measured in an unobstructed eelgrass meadow, possibly explaining the higher movement rates compared to those reported in other studies on juvenile cod.

It is interesting that only Gadus morhua aggregated over sand in high-abundance years. Juvenile $G$. morhua experienced as much as a 20 -fold fluctuation in density between years, whereas juvenile $G$. ogac demonstrated only a 6-fold change. Therefore, G. ogac may not have experienced the same pressure as
G. morhua to use alternative tactics in high-abundance years. Such a difference in the interannual variability in abundance between the 2 species may stem from life-history differences. Atlantic cod spawn both inshore (Hutchings et al. 1994) and offshore (Templeman 1979), have pelagic eggs (Scott \& Scott 1988) and often rely on local hydrography (i.e. retention areas) for survival (de Young \& Rose 1993, Bradbury et al. 1999, Page et al. 1999). Consequently, the recruitment of juvenile Atlantic cod to inshore areas should be expected to be highly variable. In contrast, G. ogac spawn inshore with demersal eggs (Scott \& Scott 1989) and may therefore be less prone to hydrographic effects associated with recruitment variability (Bradbury et al. 2003).

Gadus morhua expand their range during years of higher abundance (Rose \& Leggett 1991, Swain \& Wade 1993, Anderson \& Gregory 2000). Although we did not measure range expansion directly, it is interesting to note that substantive catches of juvenile cod in sand habitat were restricted to high-abundance years. Such an observation is consistent with the densitydependent spillover effect, but inconsistent with a carefully executed study in Newfoundland where no effect of density was found on range contraction in juvenile cod (Schneider et al. 1997). Differences between the observations in the present study and the analysis by Schneider et al. (1997) may be an issue of scale. Schneider et al. (1997) analysed catch data over a $1500 \mathrm{~km}$ range of coastline, and therefore results could have been affected by larval supply due to localised spawning success of several populations (Hutchings et al. 1994). Our study was restricted to a bay scale (i.e. $<30 \mathrm{~km}$ ), and previous work within this bay had shown that differential habitat use patterns by juvenile cod were not the result of larval supply (Laurel et al. 2003a). However, based on our results, a more likely explanation is that the increased schooling and aggregation of juvenile cod in high-abundance years masks the effects of geographic expansion. That is, the high variance associated with schooling may outweigh the lower variance indicative of range expansion. However, it remains to be determined whether the patterns of distribution observed in this study are relevant at larger scales.

In summary, field sampling and laboratory observations demonstrated that juvenile cod aggregate more over unstructured habitats (i.e. unvegetated sand) compared to overstructured habitats, i.e. eelgrass. In every year examined, higher densities of both species of juvenile cod were found in eelgrass, suggesting unvegetated sand is an unfavourable habitat. It is possible that aggregating over sand is a means of offsetting the costs (i.e. high risk and low food) associated with using these habitats. Aggregation of Gadus 
morhua also increased over sand sites in years when abundance in eelgrass habitats was high, indicating this behaviour is density-dependent. Mark-recapture experiments suggested that juvenile cod are not as site-attached as previously reported, and that aggregations are likely the result of movement in and out of sites rather than mortality over time. Video analysis also demonstrated that juvenile cod form more cohesive shoals over sand, consistent with the interpretation of field catch data. Together, these data underscore the importance of considering density along with behavioural flexibility when evaluating habitat suitability in fish.

Acknowledgements. This project was supported by NSERC Strategic Projects Grant 202034. We would like to also thank Parks Canada (Terra Nova National Park) for providing accommodations and access to facilities, and the Department of Fisheries and Oceans for boats and motors. We are also indebted to J. Anderson, L. Copeman, D. Cote, P. Frampton, D. Gibson, A.-M. Gorman, D. Ings, M. O. T. Lander, A. Ogilvie, P. Sargent and N. Wells for help with seine surveys and mark-recapture effort.

\section{LITERATURE CITED}

Anderson JT, Gregory RS (2000) Factors regulating survival of northern cod (NAFO 2J3KL) during their first 3 years of life. ICES J Mar Sci 57(2):349-359

Andorfer K (1980) The shoal behaviour of Leucaspius delineatus (Heckel) in relation to ambient space and the presence of a pike, Esox lucius. Oecologia 47:137-140

Bell JD, Pollard DA (1989) Ecology of fish assemblages and fisheries associated with seagrasses. In: Larkum AWD, McCoomb AJ, Shepherd SA (eds) Biology of seagrasses; a treatise on the biology of seagrasses with special reference to the Australian region. Elsevier, Amsterdam, p 565-609

Bertram BCR (1978) Living in groups: predators and prey. Chapter 3. In: Krebs JR, Davies NB (eds) Behavioural ecology, 1st edn. Blackwell, Oxford, p 64-96

Bogstad B, Lilly GR, Mehl S, Palsson OK, Stefansson G (1994) Cannibalism and year-class strength in Atlantic cod (Gadus morhua L.) in arcto-boreal ecosystems (Barents Sea, Iceland, and eastern Newfoundland). ICES Mar Sci Symp 198:576-599

Bradbury I, Snelgrove P, Fraser S (1999) Transport and development of cod eggs and larvae in Placentia Bay (3Ps) Newfoundland, 1997-1998. Canadian Stock Assessment Research Document 99/71, Dept Fisheries \& Oceans, St. John's, Nfld

Bradbury IR, Snelgrove PVR, Pepin P (2003) Passive and active behavioural contributions to patchiness and spatial pattern during the early life history of marine fishes. Mar Ecol Prog Ser 257:233-245

Bronmark C, Miner JG (1992) Predator-induced phenotypical change in body morphology in crucian carp. Science 258: 1348-1350

Brown JA (1984) Parental care and the ontogeny of predatoravoidance in two species of centrarchid fish. Anim Behav 32:113-119

Calvert WH, Hedrick LE, Brower LP (1979) Mortality of the monarch butterfly, Danaus plexippus: avian predation at five over-wintering sites in Mexico. Science 204:847-851

Connell SD, Jones GP (1991) The influence of habitat complexity on postrecruitment processes in a temperate reef fish population. J Exp Mar Biol Ecol 151:271-294

Dagum C (1985) Lorenz curve. In: Kolz S, Johnson NL (eds) Encyclopedia of statistical sciences. Wiley \& Sons, New York, p 156-161

Dalley EL, Anderson JT (1997) Age-dependent distribution of demersal juvenile Atlantic cod (Gadus morhua) in inshore/offshore Northeast Newfoundland. Can J Aquat Sci 54(Suppl 1):168-176

de Young B, Rose GA (1993) On recruitment and distribution of Atlantic cod (Gadus morhua) off Newfoundland. Can J Fish Aquat Sci 50 (12):2729-2741

Edgar GJ, Shaw C (1995) The production and trophic ecology of shallow-water fish assemblages in southern Australia. III. General relationships between sediments, segrasses, invertebrates and fishes. J Exp Mar Biol Ecol 194:53-81

Foster WA, Treherne JE (1981) Evidence for the dilution effect in the selfish herd from fish predation on a marine insect. Nature 295:466-467

Fraser S, Gotceitas V, Brown JA (1995) Interactions between age-class of Atlantic cod and their distribution among bottom substrates. Can J Fish Aquat Sci 53(2):305-314

Freeman MC (1995) Movements by two small fishes in a large stream. Copeia 1995:361-367

Fretwell SD, Lucas HL Jr (1970) On territorial behavior and other factors influencing habitat distributions in birds. Acta Biotheor 19:16-36

Godin JG (1997) Evading predators: habitat selection: patterns of spatial distribution from behavioural decisions. In: Godin JG (ed) Behavioural ecology of teleost fishes. Oxford University Press, Oxford

Gotceitas V, Brown JA (1993) Substrate selection by juvenile Atlantic cod (Gadus morhua): effects of predation risk. Oecologia 93:31-37

Gotceitas V, Colgan P (1989) Predator foraging success and habitat complexity: quantitative test of the threshold hypothesis. Oecologia 80:158-166

Gotceitas V, Fraser S, Brown JA (1995) Habitat use by juvenile Atlantic cod (Gadus morhua) in the presence of an actively foraging and non-foraging predator. Mar Biol 123: 421-430

Gotceitas V, Fraser S, Brown JA (1997) Use of eelgrass beds (Zostera marina) by juvenile Atlantic cod (Gadus morhua). Can J Fish Aquat Sci 54:1306-1319

Grant SM, Brown JA (1998a) Nearshore settlement and localized populations of Age 0 Atlantic cod (Gadus morhua) in shallow coastal waters of Newfoundland. Can J Fish Aquat Sci 55:1317-1327

Grant SM, Brown JA (1998b) Diel foraging cycles and interactions among juvenile Atlantic cod (Gadus morhua) at a nearshore site in Newfoundland. Can J Fish Aquat Sci 55: $1307-1316$

Gregory RS, Anderson S (1997) Substrate selection and use of protective cover by juvenile Atlantic cod Gadus morhua in inshore waters of Newfoundland. Mar Ecol Prog Ser 146:9-20

Hastings PA (1991) Flexible responses to predators in a marine fish. Ethol Ecol Evol 3:177-184

Heck KL Jr, Hays G, Orth RJ (2003) Critical evaluation of the nursery role hypothesis for seagrass meadows. Mar Ecol Prog Ser 253:123-136

Heggenes J, Northcote TG, Peter A (1991) Spatial stability of cutthroat trout (Oncorhynchus clarkii) in a small, coastal stream. Can J Fish Aquat Sci 48:757-762 
Houde E (1987) Fish early life dynamics and recruitment variability. Am Fish Soc Symp 2:17-29

Hutchings JA, Myers RA, Lilly GR (1994) Geographic variation in the spawning of Atlantic cod, Gadus morhua, in the Northwest Atlantic. Can J Fish Aquat Sci 50:2457-2467

Kramer DL, Rangley RW, Chapman LJ (1997) Habitat selection: patterns of spatial distribution from behavioural decisions. In: Godin JG (ed) Behavioural ecology of teleost fishes. Oxford University Press, Oxford, p 37-80

Krebs JR, Davies NB (1991) Behavioral ecology, 3rd edn. Blackwell Scientific, Boston

Laurel BJ (2003) Interactions of predators, habitat and conspecifics on the coastal distribution of Age 0 juvenile cod (Gadus spp.) in Newfoundland. PhD thesis, Department of Cognitive and Behavioural Ecology, Memorial University of Newfoundland, St. John's

Laurel BJ, Gregory RS, Brown JA (2003a) Settlement and distribution of Age-0 juvenile cod, Gadus morhua and G. ogac, following a large-scale habitat manipulation. Mar Ecol Prog Ser 262:241-252

Laurel BJ, Gregory RS, Brown JA (2003b) Predator distribution and habitat patch area determine predation rates on Age-0 juvenile cod Gadus spp. Mar Ecol Prog Ser 251: 245-254

Lavin PA, McPhail JD (1987) Morphological divergence and the organization of trophic characters among lacustrine populations of the threespine stickleback (Gasterosteus aculeatus). Can J Fish Aquat Sci 44:1820-1829

Levin PS (1991) Effects of microhabitat on recruitment variation in a Gulf of Maine reef fish. Mar Ecol Prog Ser 75: 183-189

Lindholm JB, Auster PJ, Kaufman LS (1999) Habitat-mediated survivorship of juvenile (0-year) Atlantic cod Gadus morhua. Mar Ecol Prog Ser 180:247-255

Linehan JE, Gregory RS, Schneider DC (2001) Predation risk of age 0 cod (Gadus morhua) relative to depth and substrate in coastal waters. J Exp Mar Biol Ecol 263:25-44

Lough RG, Valentine PC, Potter DC, Auditore PJ, Bolz GR, Neilson JD, Perry RI (1989) Ecology and distribution of juvenile cod and haddock in relation to sediment type and bottom currents on eastern Georges Bank. Mar Ecol Prog Ser 56:1-12

MacCall AD (1990) Dynamic geography of marine fish populations. University of Washington Press, Seattle

Magurran AE, Pitcher TJ (1983) Foraging, timidity and shoal size in minnows and goldfish. Behav Ecol Soc 12:142-152

Magurran AE, Pitcher TJ (1987) Provenance, shoal size and the sociobiology of predator-evasion behaviour in minnow shoals. Proc R Soc Lond B Biol Sci 229:439-465

Matilla J, Chaplin G, Eilers MR, Heck KL Jr, O'Neal JP, Valentine JF (1999) Spatial and diurnal distribution of invertebrate and fish fauna of a Zostera marina bed and nearby unvegetated sediments in Damariscortta River, Maine (USA). J Sea Res 41:321-332

Methven DA, Bajdik C (1994) Temporal variation in size and abundance of juvenile Atlantic cod (Gadus morhua) at an inshore site off eastern Newfoundland. Can J Fish Aquat Sci 51:78-90

Milinski M (1979) Can an experienced predator overcome the confusion of swarming prey more easily? Anim Behav $27: 1122-1126$

Milinski M (1985) Risk of predation taken by parasitised sticklebacks under competitiaon for food. Behaviour 93: 203-216

Mittelbach GG (1986) Predator-mediated habitat use: some consequences for species interactions. Environ Biol Fishes 16:159-169
Neill St J SR, Cullen JM (1974) Experiments on whether schooling by their prey affects the hunting behaviour of cephalopod and fish predators. J Zool (Lond) 172:549-569

Orth RJ, Heck KL Jr, van Montfrans J (1984) Faunal communities in seagrass beds: a review of the influence of plant structure and prey characteristics on predator-prey relationships. Estuaries 7:339-350

Page FH, Sinclair M, Naime CE, Loder JW, Losier RW, Berrien PL, Lough RG (1999) Cod and haddock spawning on Georges Bank in relation to water residency times. Fish Oceanogr 8:212-226

Phinney DE, Miller DM, Dahlberg ML (1973) Mass-marking young salmonids with florescent pigment. Trans Am Fish Soc 96:157-162

Pitcher TJ (1986) Functions of shoaling behaviour in teleosts. In: Pitcher TJ (ed) The behaviour of teleost fishes. Chapman \& Hall, London, p 294-337

Pitcher TJ, Magurran AE, Winfield I (1982) Fish in larger shoals find food faster. Behav Ecol Soc 10:149-51

Radabaugh DC (1989) Seasonal colour changes and shifting anti-predator tactics in darters. J Fish Biol 34:679-685

Rahel FJ, Stein RA (1988) Comple predator-prey interactions and predator intimidation among crayfish, piscivorous fish and small benthic fish. Oecologia 75:94-98

Rose GA, Leggett WC (1991) Effects of biomass-range interactions on catchability of migratory demersal fish by mobile fisheries: an example of Atlantic cod (Gadus morhua). Can J Fish Aquat Sci 48:843-848

Ruzzante DE, Taggart CT, Cook D (1998) A nuclear DNA basis for shelf and bank-scale population structure in NW Atlantic cod (Gadus morhua): Labrador to Georges Bank. Mol Ecol 7:1663-1680

Savino JF, Stein RA (1982) Predator-prey interactions between largemouth bass and bluegills as influenced by simulated submersed vegetation. Trans Am Fish Soc 11: 255-266

Schneider DC, Methven DA, Dalley EL (1997) Geographic contraction in juvenile fish: a test with northern cod (Gadus morhua) at low abundances. Can J Fish Aquat Sci 54(Suppl 1):187-199

Schneider DC, Bult T, Gregory RS, Methven DA, Ings DW, Gotceitas V (1999) Mortality, movement and body size: critical scales for Atlantic cod Gadus morhua in the northwest Atlantic. Can J Fish Aquat Sci 56(Suppl 1):180-187

Schroeder RE (1987) Effects of patch reef size and isolation on coral reef fish recruitment in Hawaii. Bull Mar Sci 41(2): 441-451

Scott WB, Scott MG (1988) Atlantic fishes of Canada. Can Bull Fish Aquat Sci 219

Sih A (1987) Predators and prey lifestyles: an evolutionary and ecological overview. In: Kerfoot WC, Sih A (eds) Predation: direct and indirect impacts on aquatic communities. University Press of New England, Hanover, NH

Sogard SM (1989) Colonization of artificial seagrass by fishes and decapod crustaceans: importance of proximity to natural eeglgrass. J Exp Mar Biol Ecol 133:15-37

Stott B (1967) The movements and population densities of roach (Rutilus rutilus (L.)) and gudgeon (Gobio gobio (L.)) in the River Mole. J Anim Ecol 36:407-423

Swain DP, Wade EJ (1993) Density-dependent geographic distribution of Atlantic cod (Gadus morhua) in the southern Gulf of St. Lawrence. Can J Fish Aquat Sci 50:725-733

Tallmark B, Evans S (1986) Substrate-related differences in antipredator behaviour of two gobiid fish species and the brown shrimp, and their adaptive value. Mar Ecol Prog Ser 29:217-222

Taylor E (1990) Phenotypic correlates of life-history variation 
in juvenile Chinook salmon, Oncorhynchus tshawytscha. J Anim Ecol 59:455-468

Templeman W (1979) Migration and intermingling of stocks of Atlantic cod, Gadus morhua, of the Newfoundland and adjacent areas from tagging in 1962-66. Res Bull ICNAF 14:5-50

Tremblay D, Fitzgerald G (1979) Social organization as an antipredator strategy in fish. Nat Can 105:411-413

Tupper M, Boutilier RG (1995a) Effects of habitat on settlement, growth, and post-settlement survival of Atlantic cod (Gadus morhua). Can J Fish Aquat Sci 52:1834-1841

Tupper M, Boutilier RG (1995b) Size and priority at settlement determine growth and competitive success of juvenile Atlantic cod. Mar Ecol Prog Ser 118:295-300

Editorial responsibility: Charles Peterson (Contributing Editor), Morehead City, North Carolina, USA
Virnstein RW, Curran MC (1986) Colonization of artificial seagrass versus time and distance from source. Mar Ecol Prog Ser 29:279-288

Weihs D (1975) Some hydrodynamical aspects of fish schooling. In: Wu T, Brokaw C, Brennen C (eds) Swimming and flying in nature. Plenum Press, New York, p 703-718

Werner EE, Gilliam JF (1984) The ontogenetic niche and species interactions in size-structured populations. Annu Rev Ecol Syst 15:393-425

Williams PJ, Brown JA (1991) Developmental changes in foraging-predator avoidance trade-offs in larval lumpfish Cyclopertus lumpus. Mar Ecol Prog Ser 76:53-60

Ydenberg RC, Dill LM (1986) The economics of fleeing from predators. Adv Stud Behav 16:229-249

Submitted: June 9, 2003; Accepted: November 17, 2003 Proofs received from author(s): April 26, 2004 